\title{
Catalytic Dehydration of 1-Propanol Over Silica Containing Sulfonic Acid Groups
}

\author{
Mustapha Mokhtaria ${ }^{a}$ Leila Kharbouche ${ }^{a}, H_{\text {adj Hamaizi }}^{a}$ (iD \\ ${ }^{a}$ Laboratoire de Synthèse Organique Appliquée, Département de chimie, Faculté des Sciences Exactes et \\ Appliquées, Université Oran1-ABB, Oran-Menaouer 31000, Algeria.
}

Received: October 24, 2018; Revised: December 27, 2018; Accepted: February 19, 2019

\begin{abstract}
Mesoporous silica with strongly acid sulfonic sites were synthesized and used as catalytic supports for catalytic dehydration of 1-propanol. This porous material with a large surface area and high porosity were prepared by a simplified sol-gel in an acidic medium and impregnated easily by $-\mathrm{SO}_{3} \mathrm{H}$ groups. The experimental results indicate that the very strong acidic sites contained on the surface are the seats of the reaction involving two molecules of n-propanol. By hydrogen bonding, ether compounds as well as the corresponding alkene are obtained in appreciable yield.
\end{abstract}

Keywords: Mesoporous silica, Dehydration, Catalysis, 1-Propanol, Ethers.

\section{Introduction}

Mesoscopically ordered mesoporous silica materials have attracted a wide interest since their discovery in the early 1990 's ${ }^{1}$ due to their diverse potential applications areas; including catalysis, filtration and chromatography. Supramolecular surfactant aggregates are used as structure directing agents in organics during condensation, leading to mesoscopically ordered surfactant-inorganic composites. Silica mesoporous materials have opened the field of investigation in many organic reactions until then considered laborious and source of pollution. Used as catalyst supports when the surface is activated by redox, acidic or basic functional groups, these materials have active sites that can be the site of chemical reactivity of adsorbed organic molecules ${ }^{2-5}$. In neutral medium, Bagshaw et al. ${ }^{6}$ synthesized a variety of materials called MSU-X using polyoxyethylene (PEO) surfactants as structuring agents. These materials have a "wormhole" or cubic structure with a much larger pore diameter than that usually observed in MCM-41 ${ }^{7}$.Other studies of this type of materials are reported by Huo et al. ${ }^{8}$, Ryoo et al. ${ }^{9}$ and Richer and Mercier ${ }^{10}$ which describes the textural properties. The wormhole channel motif is a potentially important structural feature for favorable catalytic reactivity, in part, because channel branching within the framework can facilitate access to reactive sites on the framework walls. Wormhole structures can also have relatively small fundamental particle sizes $(<200$ $\mathrm{nm}$ ), which result in complementary textural mesoporosity for the more efficient transport of reagents to framework reaction centers ${ }^{11}$. A number of studies have investigated the dehydration reaction of primary and branched alcohols, with obtaining the corresponding olefin as the major product and the formation of monoether. It has been known that alcohols undergo thermal decomposition in two ways:

$$
\begin{gathered}
\mathrm{RCH}_{2} \mathrm{CH}_{2}-\mathrm{OH} \rightarrow \mathrm{RCH}=\mathrm{CH}_{2}(\text { alkene })+\mathrm{H}_{2} \mathrm{O} \\
\mathrm{RCH}_{2} \mathrm{CH}_{2}-\mathrm{OH}+\mathrm{RCH}_{2} \mathrm{CH}_{2}-\mathrm{OH} \rightarrow \\
\mathrm{RCH}_{2} \mathrm{CH}_{2}-\mathrm{O}-\mathrm{RCH}_{2} \mathrm{CH}_{2}(\text { ether })+\mathrm{H}_{2} \mathrm{O}
\end{gathered}
$$

If the reaction is not sufficiently heated, the alcohols do not dehydrate to form alkenes, but react with one another to form ethers. The success of this procedure depends on the temperature. At $110^{\circ}$ to $130^{\circ} \mathrm{C}$ an $\mathrm{SN}_{2}$ reaction of the alcohol conjugate acid leads to an ether product. At higher temperatures (over $150^{\circ} \mathrm{C}$ ) $\mathrm{E}_{2}$ elimination takes place. These experiments were performed in the presence of metal oxides, microporous solids and commercial zeolites ${ }^{12-16}$. Acid-catalyzed dehydration of small primary alcohols constitutes a specialized method of preparing symmetrical ethers. Recently, Almashhadani et al. ${ }^{17}$ investigate the bimolecular dehydration of 1-propanol and methanol with catalysts to produce di-propyl ether by appropriated selection of the catalyst. More recently, great efforts have been made to explain the processes in heterogeneously catalyzed elimination ${ }^{18}$. The ether formation (bimolecular reaction) from the hydration of alcohols on $\gamma$-aluminum oxide requires $\mathrm{OH}$ groups, oxygen and aluminum ions on the surface. The ether is formed from a surface alkoxide group and molecularly adsorbed alcohol. However, a competition exists between alkene and ether formations as investigated by Jain and Pillai ${ }^{19}$ which the conclusion was drawn that both reactions are surface reactions but requiring different types of active sites.

Accordingly, the present work investigates the textural mesoporosity of samples of the mesoporous silica from nonionic surfactants such as Di-block copolymers $\mathrm{C}_{\mathrm{n}} \mathrm{H}_{2 \mathrm{n}+1}-(\mathrm{EO})$ $x$ as directing agents using tetraethylorthosilicate TEOS as silica source according to a simplifiedsynthesis protocol. Mesoporous silica containing $-\mathrm{SO}_{3} \mathrm{H}$ acid groups are tested for the catalytic dehydration of 1-propanol. 


\section{Materials and Methods}

\subsection{Chemicals}

All surfactants are supplied by Acros Organics whose trade names and empirical formulas are: Polyoxyethylene (20) cetyl ether Brij ${ }^{\circledR} 58: \mathrm{C}_{16} \mathrm{H}_{33}\left(\mathrm{OC}_{2} \mathrm{H}_{4}\right)_{20} \mathrm{OH} ; \mathrm{M} \sim 1124 \mathrm{~g} /$ mol.; HLB:15.7; Polyoxyethylene (20) stearyl ether Brij ${ }^{\circledR 78:}$ $\mathrm{C}_{18} \mathrm{H}_{37}\left(\mathrm{OC}_{2} \mathrm{H}_{4}\right)_{20} \mathrm{OH} ; \mathrm{M}=1151.5 \mathrm{~g} / \mathrm{mol}$; $\mathrm{HLB}=15.3$ and cetyltrimethyl ammonium bromide CTAB: $\mathrm{C}_{19} \mathrm{H}_{42} \mathrm{BrN}$; $\mathrm{M}=364.5 \mathrm{~g} / \mathrm{mol}$. Tetraethylorthosilicate TEOS (Fluka) is used as silica source. For each synthesis, deionized water and prepared $\mathrm{HCl}$ (analytical reagent) 1mole.L-1 by volumetric dilution of concentrated acid from SigmaAldrich. We use the 1-propanol: $\mathrm{CH}_{3} \mathrm{CH}_{2} \mathrm{CH}_{2}-\mathrm{OH}$ at $99 \%$ $(\mathrm{d}=0.804)$ purity and commercialized by Riedel-de Haen (impurities noted: aldehyde $\mathrm{CH}_{3} \mathrm{COCH}_{3}: 0.05 \%$, Free acid: 0.002\%; water: 0.05\%). PSS Poly-(4-styrene-sulfonic acid) solution $\mathrm{C}_{8} \mathrm{H}_{8} \mathrm{O}_{3} \mathrm{~S}\left(\mathrm{Mw} \sim 75,000,18 \%\right.$ in $\left.\mathrm{H}_{2} \mathrm{O}\right)$ and n-hexane were purchased from Sigma-Aldrich.

\subsection{Materials synthesis}

The synthesis protocol adopted in this work consists of mixing of an aqueous solution of the non ionic surfactant with an aqueous $\mathrm{HCl} 1 \mathrm{~mol} . \mathrm{L}^{-1}$ solution at constant stirring for $60 \mathrm{~min}$. The requisite amount of TEOS was added by stirring for 24 hours at room temperature. The mixture was then heated at $373 \mathrm{~K}$ overnight without stirring. The precipitated solid product was recovered by filtration, washed and dried at $353 \mathrm{~K}$. For example, $2 \mathrm{~g}$ of Brij ${ }^{\circledR} 58$ in $30 \mathrm{~g}$ of deionized water were stirred for $10 \mathrm{~min}$. before adding $120 \mathrm{~mL}$ of $\mathrm{HCl} 1 \mathrm{~mol} . \mathrm{L}^{-1}$ solution. An amount of TEOS $(9 \mathrm{~g})$ was added to this homogeneous mixture and kept under vigorous stirring for 24 hours. The mixture was introduced in a closed glass tube and heated at $373 \mathrm{~K}$ for 48 hours without stirring. The resulting white precipitates were filtered out, washed with copious amounts of distilled water, and allowed to air dry at room temperature for $24 \mathrm{~h}$. The surfactant was removed by calcinations in air at $823 \mathrm{~K}$ for $4 \mathrm{~h}$. This temperature was reached with a heating rate of $10 \mathrm{~K} \cdot \mathrm{min}^{-1}$ and a first plateau at $373 \mathrm{~K}$ for $1 \mathrm{~h}$. After the second plateau at $823 \mathrm{~K}$ for $4 \mathrm{hrs}$, the oven was cooled down at room temperature with a cooling rate of about $5 \mathrm{~K} / \mathrm{min}$ and a fine white powder was recovered. Samples are named MS58 andMS78 from synthesis using nonionic copolymers surfactants Brij ${ }^{\circledR} 58$ and $B$ rij ${ }^{\circledR} 78$ respectively.

A sample of Al-MCM41 was also prepared according to the method described by Mokaya et al. ${ }^{20}$ from the following stoichiometric molar composition with a fixed molar ratio $\mathrm{Si} / \mathrm{Al}$ of $25: \mathrm{SiO}_{2} / \mathrm{Na}_{2} \mathrm{Al}_{2} \mathrm{O}_{3} / \mathrm{C}_{16} \mathrm{TABr} / \mathrm{TMAOH} /$ $\mathrm{H}_{2} \mathrm{O}=1 / 0.013 / 0.25 / 0.2 / 40$.

\subsection{Impregnation of solids by sulfonic acid groups}

$100 \mathrm{mg}$ of the freshly prepared and calcined materials are added to $12.5 \mathrm{~mL}$ of a solution of poly-(4-styrene sulfonic acid) dissolved in $100 \mathrm{~mL}$ of $\mathrm{n}$-hexane. The mixture was shaken at room temperature for $24 \mathrm{~h}$. The product was separated by centrifugation and dried in an oven overnight. The presence or absence of strong acid sites is verified by the $\mathrm{NH}_{3}$-TPD performed on freshly impregnated samples

\subsection{Dehydration reaction procedure}

An amount of the impregnated solid is placed in a raised column on a flask containing the alcohol $(10 \mathrm{~mL})$. Heating at $371 \mathrm{~K}$ allows contact of the steam with the solid for an average of 12 or 24 hours. As the reactant vapor flows through the bed of solid particles, it undergoes a conversion that depends on the time of contact with the catalyst. The product flows through a condenser and the condensed reactant may be re vaporized to re circulate through the catalyst bed. An amount is then taken to be analyzed by gas chromatography. Primary variables that were calculated include substrate conversion and selectivity. For the dehydration of n-propanol, aforementioned variables were calculated as follows:

$$
\begin{gathered}
n-\text { propanol conversion }= \\
\frac{\mathrm{n}_{(\mathrm{n}-\text { propanol })}^{\circ}-\mathrm{n}_{(\mathrm{n}-\text { propanol })}}{\mathrm{n}_{(\mathrm{n}-\text { propanol })}}
\end{gathered}
$$

Selectivity toward ether or alkene $=$

$$
\frac{\mathrm{n}_{\text {(ether or alkene })}}{\mathrm{n}_{(\mathrm{n}-\text { propanol })}+\mathrm{n}_{(\mathrm{n}-\text { propanol })}}
$$

\subsection{Characterization and analysis method}

Small-angle X-ray diffraction (XRD) patterns were recorded on anBruker D8 Discover resolution X-ray powder diffraction (XRD) using $\mathrm{Cu} K \alpha$ radiation $(\lambda=$ $0.15418 \mathrm{~nm}$ ) in the $2 \theta$ range of $0.5-20^{\circ}$ with a scanning rate of $0.5 \% \mathrm{~min}$. The X'PERTPLUS ${ }^{\circ}$ software enabled the counting of the spectra and the calculation of pore-pore distance by indexing the reflections. The $\mathrm{N}_{2}$ isotherms were measured by automated apparatus ASAP 2020 (Micromeritics) at $77 \mathrm{~K}$. Prior to $\mathrm{N}_{2}$ adsorption analysis, all samples were degassed at $673 \mathrm{~K}$ under vacuum for 4 hours. The BET surface areas were calculated based on the linear part of the BET plot ( $P /: 0.05-0.35$ range). The total pore volumes were estimated according to nitrogen uptake at a relative pressure $(\mathrm{P} / \mathrm{Po})$ of ca. 0.99 . The pore size distribution and pore diameter were derived from the desorption branch of the $\mathrm{N}_{2}$ isotherms using Barrett-Joyner-Halenda (BJH) method using the Halsey equation for multilayer adsorption for all samples. 
Morphology and particle size of the final products were observed by using scanning electron microscopy FE-SEM (JEOL-350) operating at an acceleration voltage of 20$30 \mathrm{kV}$. Transmission Electron Microscope (TEM, JEOL JEM-2010) was employed for microstructural observation. The surface acidic presence of the samples were identified by temperature programmed desorption of ammonia $\left(\mathrm{NH}_{3}-\right.$ TPD) which was carried out in a quartz micro-reactor with a thermal conductivity detector (TCD). $50 \mathrm{mg}$ of samples were pre-treated for $1 \mathrm{~h}$ in Argon flow at $723 \mathrm{~K}$ to remove strongly bound species then cooled to $373 \mathrm{~K}$ and saturated with continuously flowing ammonia. Finally the samples were heated to $873 \mathrm{~K}$ in $30 \mathrm{~mL} / \mathrm{min}$ of Argon flowing at $10 \mathrm{~K} / \mathrm{min}$. The products of the dehydrogenation reaction of 1-propanol are analyzed by gas phase chromatography coupled to amass spectrometer (Perichrom2100 coupled with 5973 MSD Agilant NETWERK) with a polar column $25 \mathrm{~m}$ in height and $0.22 \mathrm{~mm}$ in diameter; stationary phase: Carbowax 20M Poly ethylene glycol polar; gas carrier Helium and flow rate: $1.0 \mathrm{~mL} / \mathrm{min}$.

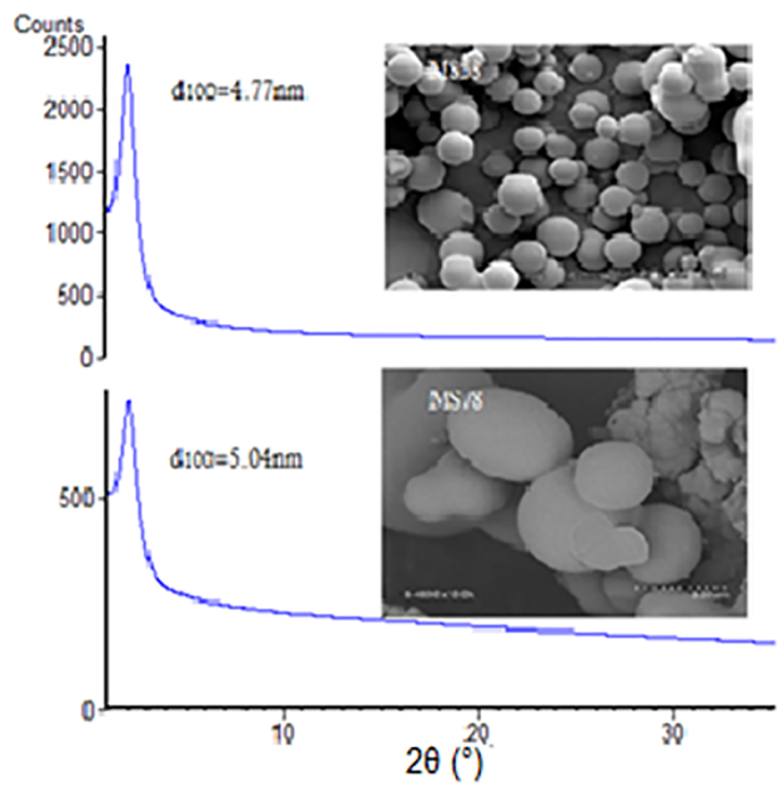

\section{Results and Discussions}

XRD patterns (Figure1) recorded on both samples from nonionic surfactants MS58 and MS78 samples show the presence of a single broad peak in the $2 \theta$ range of $1-4^{\circ}$ indicates a poorly ordered structure as usually observed for mesostructured materials with worm-like pores ${ }^{21}$. XRD pattern of Al-MCM41 sample shows two peaks indicating a more ordered pore network, which can be indexed in (100) and (200) reflections indicating an ordered $2 \mathrm{D}$ hexagonal mesostructure. If the correlation distance deduced from the main XRD peak can be attributed to the pore-pore distance, the $\mathrm{D}_{\text {pore-pore }}$ values are approximately very close $(\cong 5 \mathrm{~nm})$ for the three samples. SEM observations done on MS58 and MS78 samples show distinct spherical particles with extremely varied size $(2-7 \mu \mathrm{m})$ indicating that nucleation and growth of silica particles are not independent of each other. The silica particles of Al-MCM41 material aredistinct and uniform with a hexagonal morphology. Cubic arrangement and hexagonal disposition of pores are clearly observed by TEM for all samples as shown in Figure 2.

Figure 1. Low-angle XRD patterns of calcined samples: MS58, MS78 and Al-MCM41.
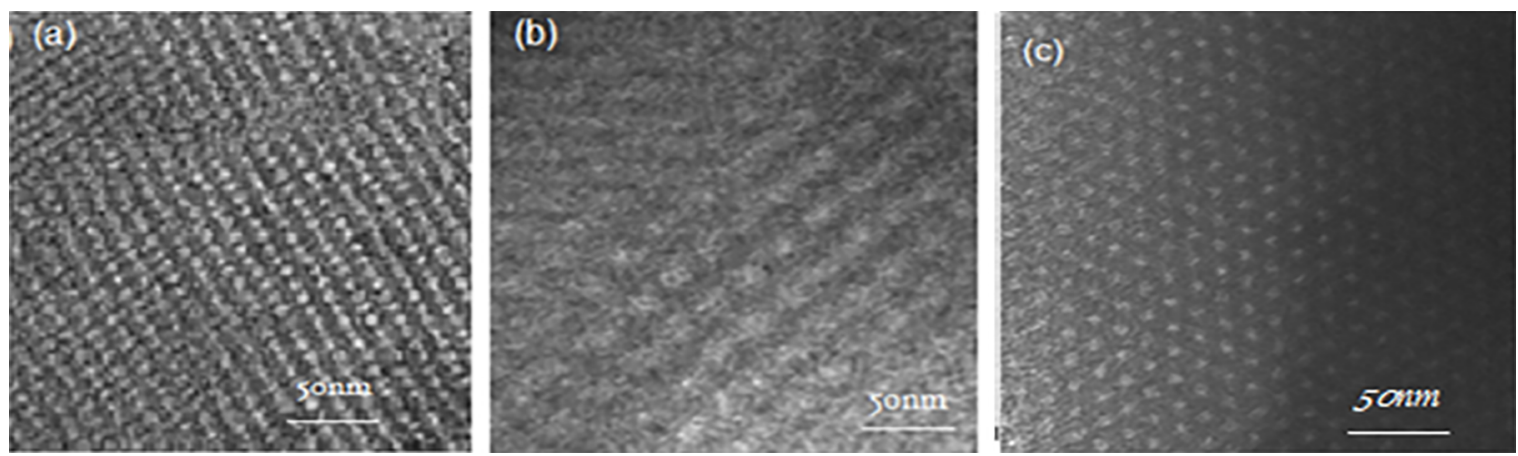

Figure 2. High resolution transmission HR-TEM of calcined samples: (a) MS58 (TEOS/Brij58); (b) MS78 (TEOS/Brij78) and (c) Al-MCM41 (TEOS/CTAB). 
Nitrogen adsorption/desorption isotherms are type IV attributed to mesoporous materials for all samples with a different shape for Al-MCM41 showing no hysteresis loop which is characteristic of textural porous materials having a narrow pore distribution of uniform size (Figure3). The other two isotherms show a hysteresis loop of $\mathrm{H} 2$ type with a slightly accentuated shape indicating regular spherical pores with narrow extremities. The textural and structural parameters of solid samples are given in Table 1. All samples exhibit high surface area (between $700-840 \mathrm{~m}^{2} / \mathrm{g}$ ) and an average pores diameter around $3 \mathrm{~nm}$. High volume pores is observed for Al-MCM41 sample $(0.83 \mathrm{~mL} / \mathrm{g})$ and the calculated value of the wall thickness (1.40 to $2.10 \mathrm{~nm})$ suggests a high relative thermal stability for these materials.

Surface acidity of the pure materials impregnated with the $-\mathrm{SO}_{3} \mathrm{H}$ acid groups is identified using $\mathrm{NH}_{3}-\mathrm{TPD}$ to evaluate the strength and type of acid sites. Often the temperature of maximum desorption (TPD peak) is used as a rough measure of the acid strength of the sorption sites.
According to a study on the presence and nature of the acidic sites ${ }^{22}$, among the limitations of the $\mathrm{NH}_{3}$-TPD method is that it can distinguish sites by sorption strength only. Moreover, desorption may proceed simultaneously from sites of different type resulting in more or less overlapping TPD peaks. The results are summarized in Figure4 with the presence of $\mathrm{NH}_{3}$ desorption peaks for the pure samples, indicating the presence of acidic sites. In sample Al-MCM41 there are two peaks at about 200 and $450{ }^{\circ} \mathrm{C}$, which last one is attributed probably to the presence of Brønsted acid sites due to the dispersion of aluminum in the matrix. The absence of this desorption peak at $450{ }^{\circ} \mathrm{C}$ in MS58 and MS78 suggests the absence of Brønsted acid sites as described by Notestein et al. ${ }^{23}$ giving its attribution to this type of acid sites. For the impregnated materials, desorption is visible around $350-450^{\circ} \mathrm{C}$ for both of MS58 and MS78 samples and much more assertive in Al-MCM-41. Therefore, an appearance of strong acid sites attributed to $-\mathrm{SO}_{3} \mathrm{H}$ groups are distributed on the silica surface of each of the materials.

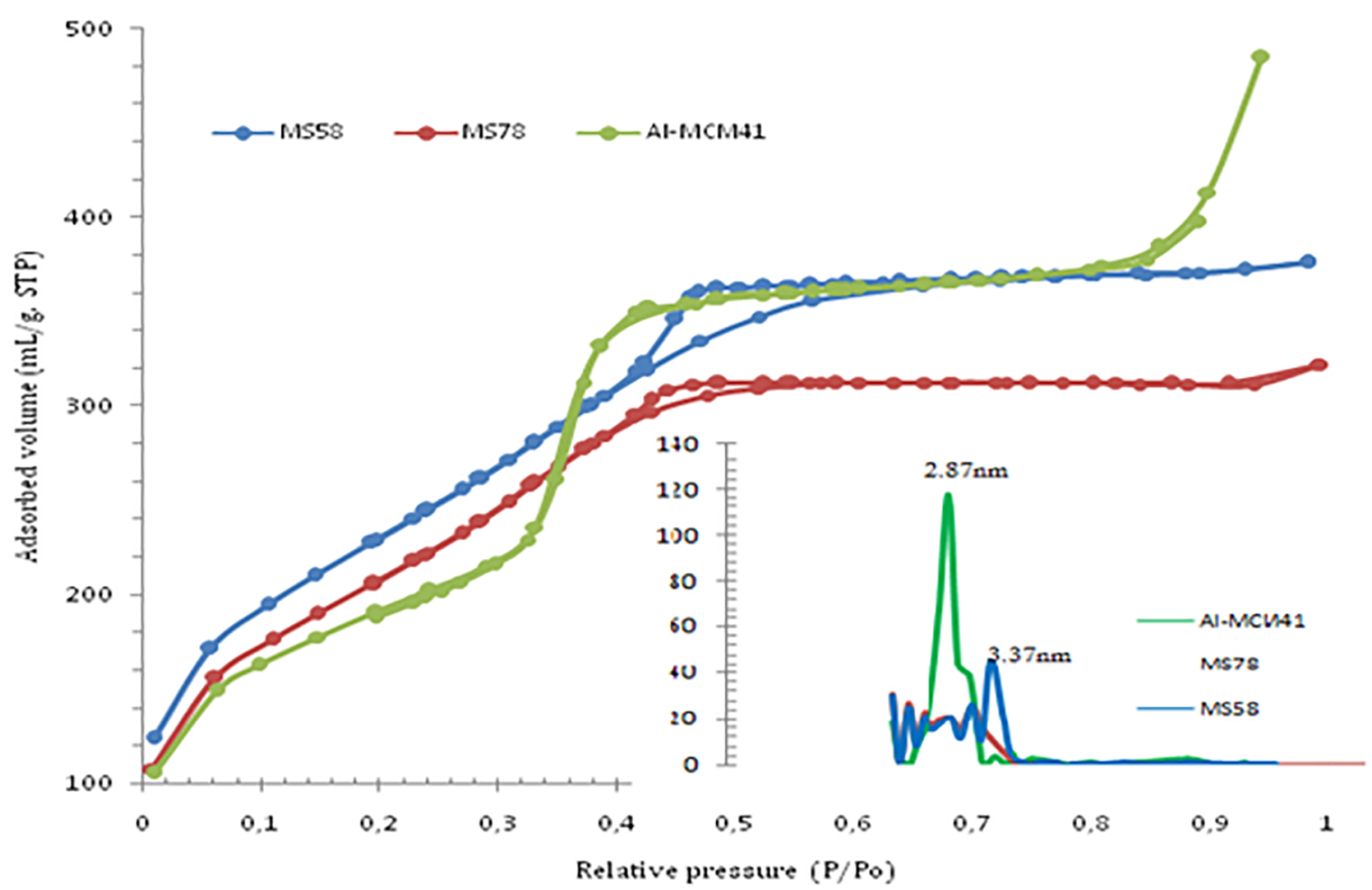

Figure 3. Nitrogen adsorption-desorption isotherms at 77K of calcined samples MS58, MS78 and Al-MCM4. Inset: Pore size distribution (PSD) obtained by BJH method applied on desorption branch.

Table 1. Textural and structural parameters of material samples calcined at $823 \mathrm{~K}$ under air for 6 hours.

\begin{tabular}{lccccc}
\hline Designation & $\mathrm{D}_{\text {pore-pore }}{ }^{\mathrm{a}} / \mathrm{nm}$ & $\boldsymbol{S}_{B E T} / \mathrm{m}^{2} \cdot \mathrm{g}^{-1}$ & $\boldsymbol{V}_{p}^{\mathrm{b}} / \mathrm{mL}^{-\mathrm{g}^{-1}}$ & $\varnothing \mathrm{BJH} / \mathrm{nm}$ & thickness $/ \mathrm{nm}^{\mathrm{c}}$ \\
\hline MS58 & 4.77 & 839 & 0.45 & 3.37 & 1.40 \\
MS78 & 5.04 & 779 & 0.35 & 3.12 & 1.92 \\
Al-MCM41 & 4.97 & 691 & 0.83 & 2.87 & 2.10 \\
\hline
\end{tabular}

${ }^{\mathrm{a}}$ Corresponding to the $\mathrm{d}$ value of the characteristic X-ray reflection of the calcined products. ${ }^{\mathrm{b}}$ Calculated at $\mathrm{P} / \mathrm{P}_{0}=0.99{ }^{\mathrm{c}}$ Determined by the calculation method BJH applied on the desorption branch. ${ }^{d}$ Silica thickness calculated $t=\left(D_{\text {pore-pore }}-\emptyset \mathrm{BJH}\right)$ 

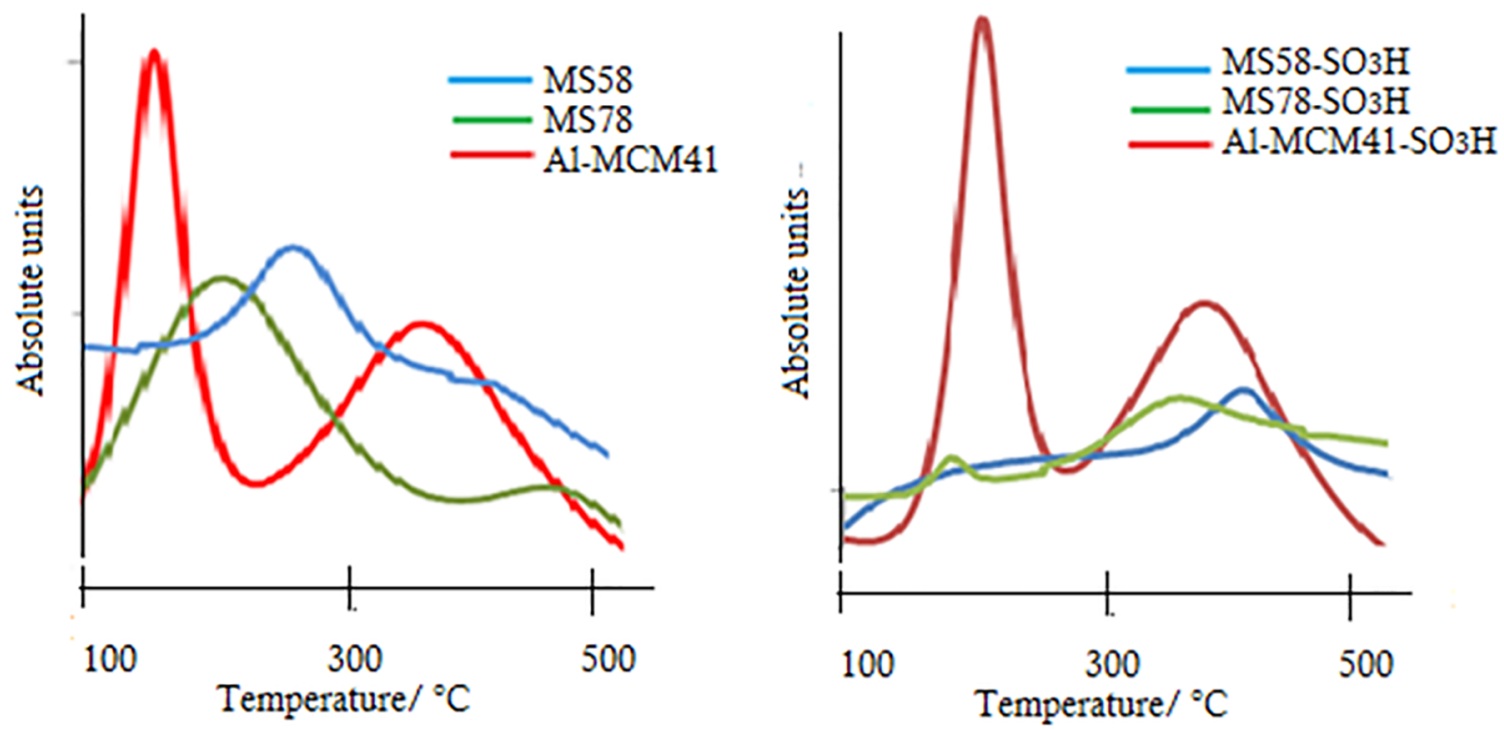

Figure 4. $\mathrm{NH}_{3}-\mathrm{TPD}$ curves for the calcined samples and impregnated $-\mathrm{SO}_{3} \mathrm{H}$ catalysts.

Chromatography detected the constituents formed during the reaction in visibly distinct retention times and based on their polarity and molecular weight; It distinguishes the intense peak corresponding to propyl alcohol $\left(t_{r}=1.62 \mathrm{~min}\right.$. $)$ as well as other constituents of significant molecular weight which are detected at longer times as illustrated in Figure 5 for MS58 solid impregnated with the acidic groups of $-\mathrm{SO}_{3} \mathrm{H}$. As each peak of a chromatogram becomes a "fingerprint" of the compound, identification by mass spectrometry leads to ether compounds (Figure 6). The mono-ether is easily identified as a product formed by dehydration of 1-propanol. Mass Spectrum MS of the Di-n-propylether shows the molecular ion at $m / z 102$; the peak at $m / z 73$ is the result of cleavage with a loss of an ethyl radical from either the n-propyl chains.Finally, the base peak at $m / z 43$ corresponds to loss of neutral aldehyde molecule $\mathrm{CH}_{2}=\mathrm{O}$ from the fragmentation at $\mathrm{m} / \mathrm{z} 73$ in a reaction producing a propyl carbenium ion. The suggested mechanism of formation of Di-n-propyl ether illustrated in Figure 7 can be explained by the proton transfers suggested to be concerted,

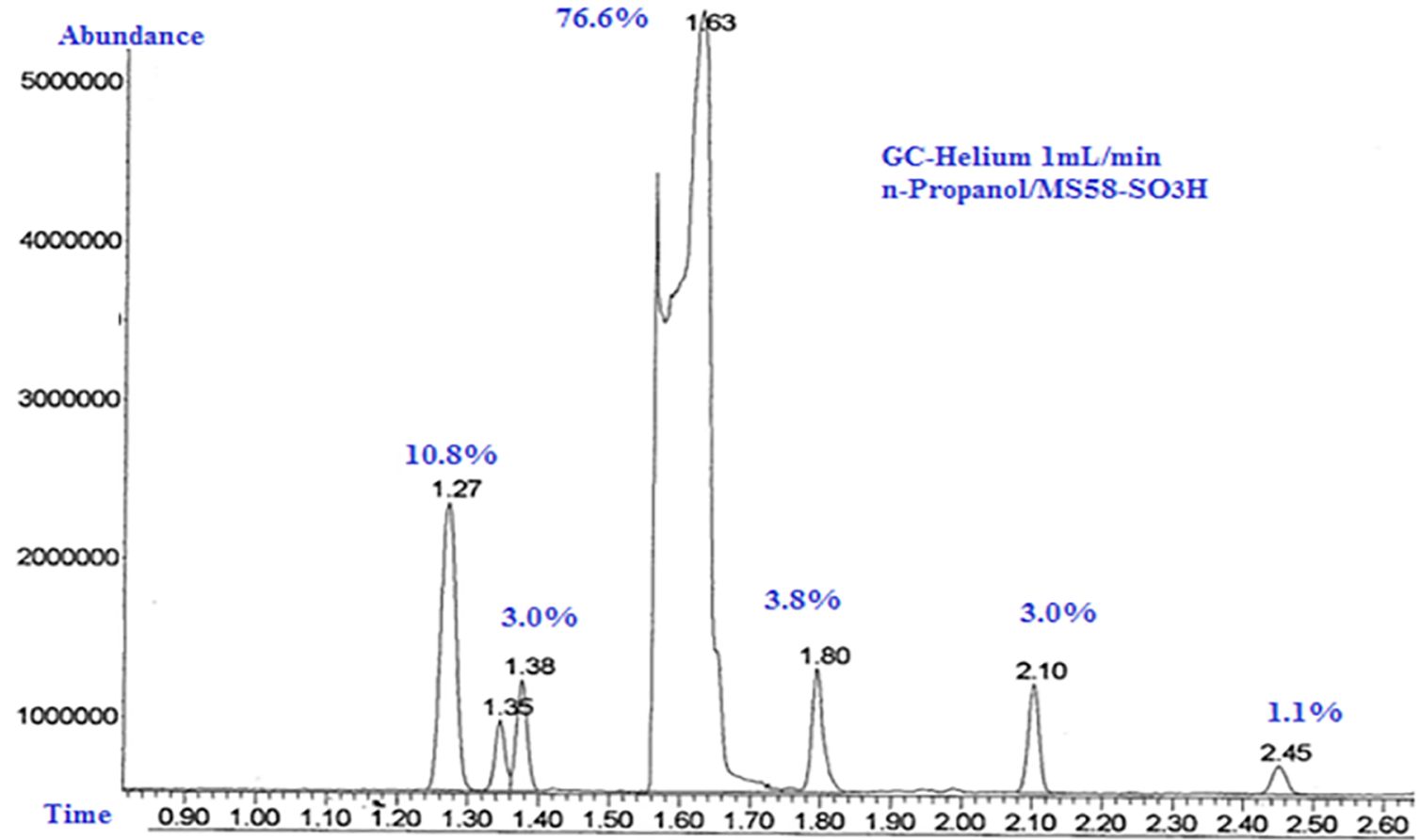

Figure 5. Chromatogram generated by a GC for n-Propanol/MS58- $\mathrm{SO}_{3} \mathrm{H}$ reaction (time contact $12 \mathrm{~h}$ at $371 \mathrm{~K}$ ). 


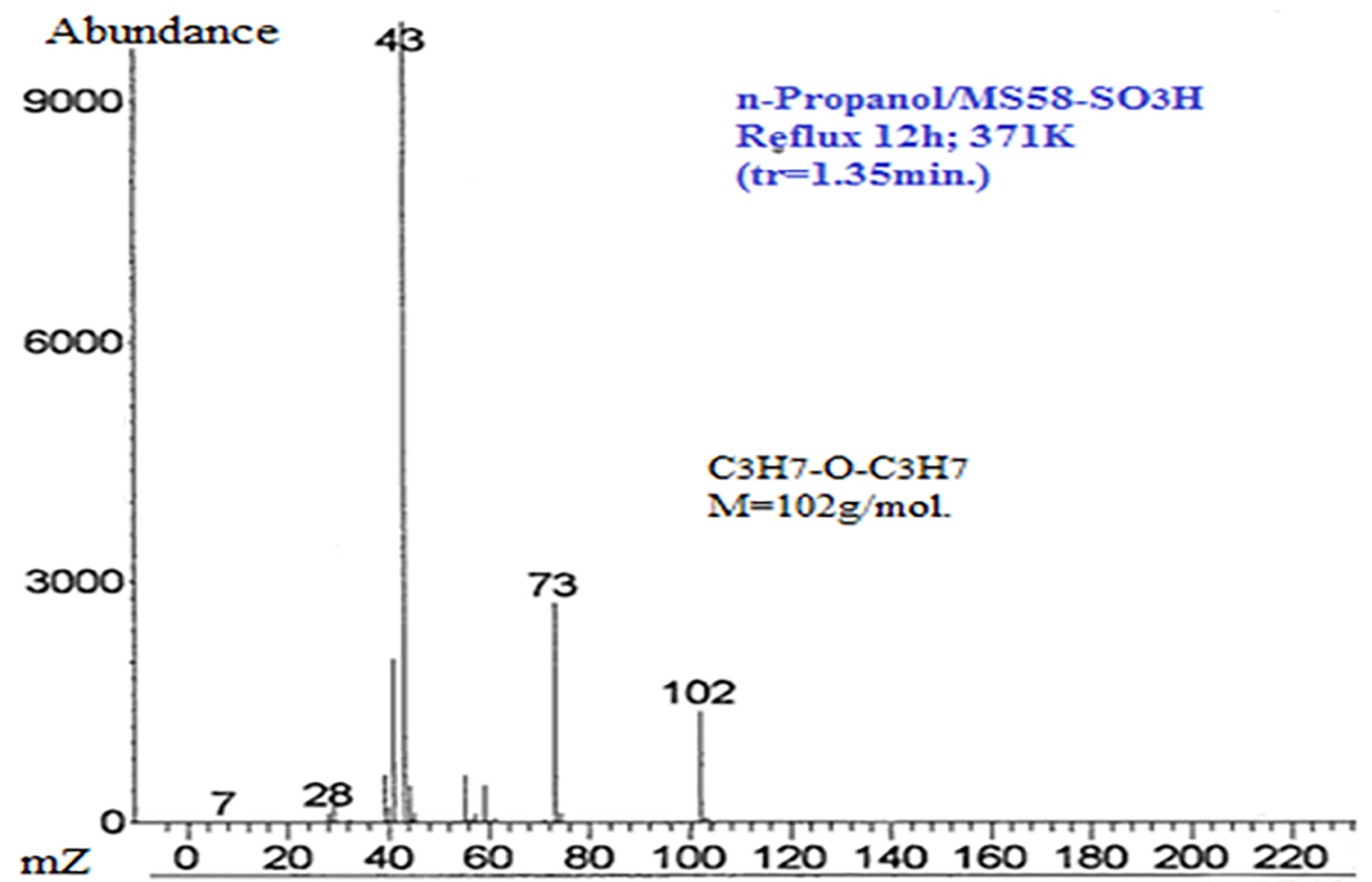

Figure 6. Mass-spectrum generated by an MS-GC coupled for n-propanol/MS58- $\mathrm{SO}_{3} \mathrm{H}$ at retention time tr=1.35min.

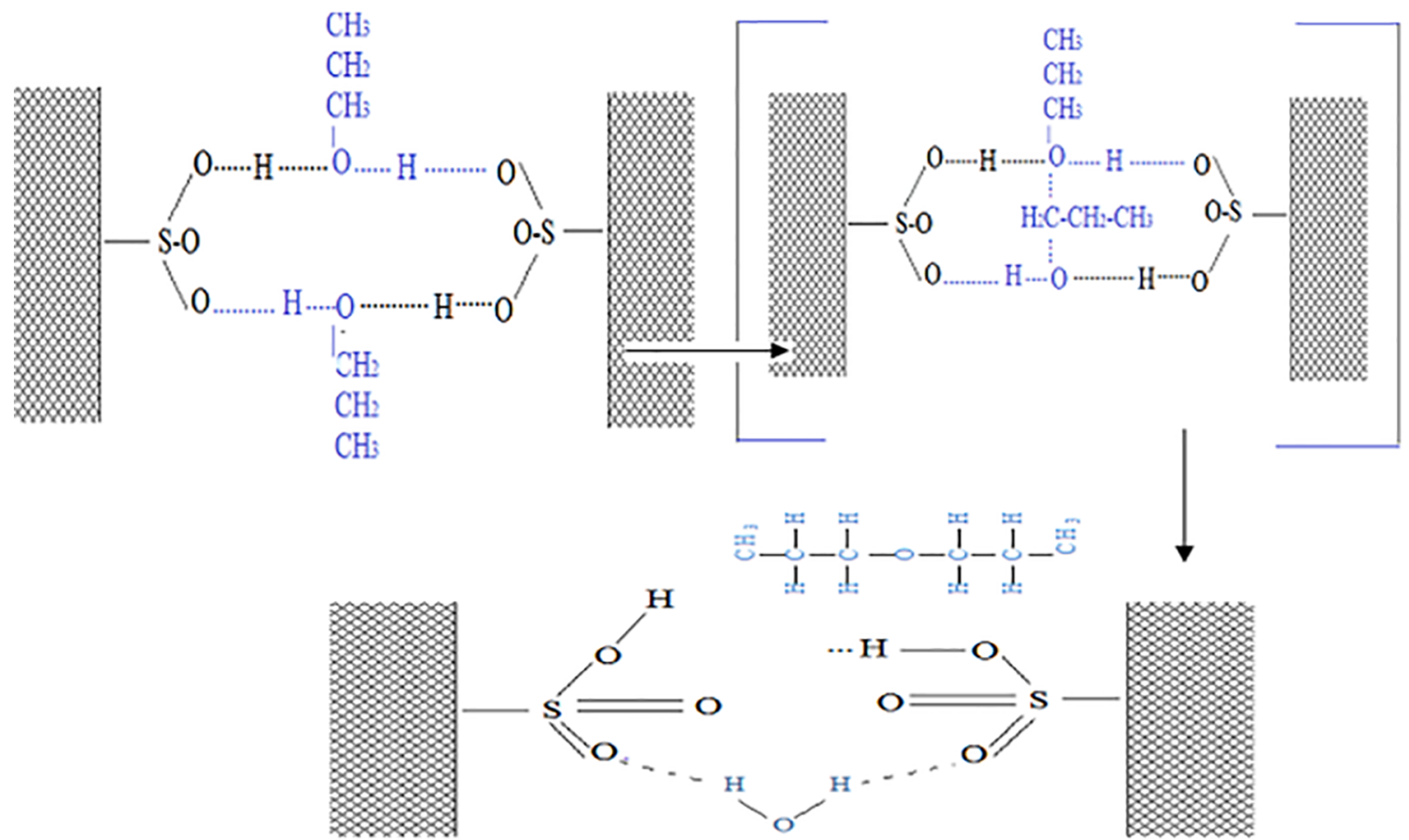

Figure 7. Suggested mechanism of 1-propanol dehydration catalyzed by acidic groups $-\mathrm{SO}_{3} \mathrm{H}$. 
with the alcohol bonded between $-\mathrm{SO}_{3} \mathrm{H}$ groups as shown in the ethanol dehydration reaction ${ }^{24,25}$. Nevertheless, as the ether yield seems less important, it is likely that the water is a reaction inhibitor because it competes favorably with the alcohol for the $-\mathrm{SO}_{3} \mathrm{H}$ groups, which are the proton donors and sites of catalysis in the solid. Often it has been observed that the rate of a catalytic reaction is strongly dependent on the concentration of $-\mathrm{SO}_{3} \mathrm{H}$ groups.

Furthermore, another reaction seems to take place when the masses of important fragments of the tri-n-propyl-ether molecule from the peak scanning located at retention time $1.80 \mathrm{~min}$. Top peak at $\mathrm{m} / \mathrm{z} 59$ followed by second and third highest peaks at $\mathrm{m} / \mathrm{z} 43$ and 101 respectively. This is formed from the molecule of mono-ether by binding a propionate ion $\mathrm{CH}_{3} \mathrm{CH}_{2} \mathrm{CH}_{2} \mathrm{O}^{-}$by articulating on the acid surface. Other interactions are possible and lead to the formation of organic intermediates that we cannot identify. Probably the precursors of these reactions are propyl carbenium $(+)$ and propionate ion (-); the first can be attributed to the formation of the corresponding alkene, and the second to the formation of the ethers. Table 2 gives the conversion rates of the propanol dehydration reaction as well as the percentages of selectivity of the final products. A longer reflux time and a large catalytic support mass lead to a higher conversion rate elsewhere, It also seems that there is no direct correlation between the textural properties of materials as catalyst supports, but it is the nature of their surface which has strongly acidic sites (Brønsted acid centers) due to the presence of sulfonic acid groups on basis of the conversion rates into ethers obtained for the three supports. However, the silanol groups also play a role in dehydrating the propanol molecule to promote the corresponding alkene.

Table 2. Results of the products from the dehydration reaction of 1-propanol in the presence of mesoporous catalytic supports functionalized with sulfonic groups. $10 \mathrm{~mL}$ of 1 -propanol; reflux temperature: $371 \mathrm{~K}$

\begin{tabular}{|c|c|c|c|c|c|c|c|}
\hline Sample & Weight /g & Time contact/hours & Conversion/ $\%$ & \multicolumn{4}{|c|}{ Selectivity $(\%)$ ethers propene Mono di others } \\
\hline MS58 & 0.062 & 12 & 35.42 & 58.49 & 21.24 & 16.92 & 3.35 \\
\hline MS78 & 0.080 & 12 & 38.82 & 66.26 & 18.56 & 10.64 & 4.54 \\
\hline Al-MCM41 & 0.150 & 24 & 52.47 & 51.63 & 22.72 & 18.64 & 7.01 \\
\hline
\end{tabular}

\section{Conclusion}

Silica amorphous materials having strong acidic sites by incorporation of sulfonic acid groups are used as catalyst supports for the dehydration reaction of n-propanol. Organic intermediates formed during the reaction such as propyl carbocation and propionate lead to the formation of mono- and di-ether compounds as well as the corresponding alkene. It is shown that the acidic sites are responsible for interactions that occur at the surface and include a bimolecular dehydration of the alcohol by association of hydrogen bonding from sulfonic acid groups. The propionate ion leads to promote molecules of ethers while carbenium ion favorites the propylene molecule.

\section{Acknowledgments}

This work is part of research project CNEPRU (University Oran1) of the Ministry of Higher Education which has provided us with financial support; the financial support of the University Oran $1-\mathrm{ABB}$ and the University of Almeria is gratefully acknowledged for characterization analyzes reported in this work.

\section{References}

1. Kresge CT, Leonowicz ME, Roth WJ, Vartuli JC, Beck JS. Ordered mesoporous molecular sieves synthesized by a liquidcrystal template mechanism. Nature. 1992;359:710-712.
2. Beck JS, Vartuli JC, Roth WJ, Leonowicz ME, Kresge CT, Schmitt KD, et al. A new family of mesoporous molecular sieves prepared with liquid crystal templates. Journal of the American Chemical Society. 1992;114(27):10834-10843.

3. Prouzet E, Cot F, Nabias G, Larbot A, Kooyman P, Pinnavaia TJ. Assembly of Mesoporous Silica Molecular Sieves Based on Nonionic Ethoxylated Sorbitan Esters as Structure Directors. Chemistry of Materials. 1999;11(6):1498-1503.

4. Zhao D, Feng J, Huo Q, Melosh N, Fredrickson GH, Chmelka BF, et al. Triblock Copolymer Syntheses of Mesoporous Silica with Periodic 50 to 300 Angstrom Pores. Science. 1998;279(5350):548-552.

5. Mokaya R, Zhou W, Jones W. A method for the synthesis of high quality large crystal MCM-41. Chemical Communications. 1999;1(1):51-52.

6. Bagshaw SA, Prouzet E, Pinnavaia TJ. Templating of mesoporous molecular sieves by nonionic polyethylene oxide surfactants. Science. 1995;269(5228):1242-1244.

7. Zhao D, Huo Q, Feng J, Chmelka BF, Stucky GD. Nonionic Triblock and Star Diblock Copolymer and Oligomeric Surfactant Syntheses of Highly Ordered, Hydrothermally Stable, Mesoporous Silica Structures. Journal of the American Chemical Society. 1998;120(24):6024-6036.

8. Huo Q, Margolese DI, Stucky GD. Surfactant Control of Phases in the Synthesis of Mesoporous Silica-Based Materials. Chemistry of Materials. 1996;8(5):1147-1160. 
9. Ryoo R, Kim JM, Shin CH, Lee JY. Synthesis and hydrothermal stability of a disordered mesoporous molecular sieve. Studies in Surface Science and Catalysis. 1997;105:45-52.

10. Richer R, Mercier L. Direct Synthesis of Functional Mesoporous Silica by Neutral pH Nonionic Surfactant Assembly:? Factors Affecting Framework Structure and Composition. Chemistry of Materials. 2001;13(9):2999-3008.

11. Zhang W, Pauly TR, Pinnavaia TJ. Tailoring the Framework and Textural Mesopores of HMS Molecular Sieves through an Electrically Neutral $\left(\mathrm{S}^{\circ} \mathrm{I}^{\circ}\right)$ Assembly Pathway. Chemistry of Materials. 1997;9(11):2491-2498.

12. Rivard JM, Zhang QL, Chuang KT. Kinetics of Aqueous-Phase catalytic dehydration of 2-Propanol. Canadian Journal of Chemical Engineering. 2001;79(4):517-523.

13. Fei J, Hou Z, Zhu B, Lou H, Zheng X. Synthesis of dimethyl ether (DME) on modified HY zeolite and modified HY zeolitesupported $\mathrm{Cu}-\mathrm{Mn}-\mathrm{Zn}$ catalysts. Applied Catalysis A: General. 2006;304:49-54.

14. Varisli D, Dogu T, Dogu G. Ethylene and diethyl-ether production by dehydration reaction of ethanol over different heteropolyacid catalysts. Chemical Engineering Science. 2007;62(18-20):53495352.

15. Roy S, Mpourmpakis G, Hong DY, Vlachos DG, Bhan A, Gorte RJ. Mechanistic Study of Alcohol Dehydration on ?-Al2O3. ACS Catalysis. 2012;2(9):1846-1853.

16. Brown AB, Emniet Reid E. The catalytic dehydration of alcohols. Journal of Physical Chemistry. 1924;28(10):1077-1081.
17. Almashhadani H, Samarasinghe N, Fernando S. Dehydration of n-propanol and methanol to produce etherified fuel additives. AIMS Energy. 2017;5(2):149-162.

18. Knözinger H. Dehydration of Alcohols on Aluminum Oxide. Angewandte Chemie. International Edition. 1968;7(10):791805 .

19. Jain JR, Pillai CN. Catalytic dehydration of alcohols over alumina: Mechanism of ether formation. Journal of Catalysis. 1967;9(4):322-330.

20. Mokaya R, Jones W. Efficient post-synthesis alumination of MCM-41 using aluminum chlorohydrate containing A1 polycations. Journal of Materials Chemistry. 1999;9(2):555561.

21. Pauly TR, Pinnavaia TJ. Pore Size Modification of Mesoporous HMS Molecular Sieve Silica with Wormhole Framework Structures. Chemistry of Materials. 2001;13(3):987-993.

22. Lónyi F, Valyon J. On the interpretation of the NH3-TPD patterns of H-ZSM-5 and H-mordenite. Microporous and Mesoporous Materials. 2001;47(2-3):293-301.

23. Ardagh MA, Bo ZY, Nauert SL, Notestein JM. Depositing $\mathrm{SiO} 2$ on A12O3: A route to tunable Brønsted acid catalysts. ACS Catalysis. 2016;6(9):6156-6164.

24. Gates BC. Catalytic Chemistry. New York: John Wiley and Sons; 1992. p. 199-204.

25. Yaripoor F, Baghaei F, Schmidt I, Perregaard J. Catalytic dehydration of methanol to dimethyl ether (DME) over solidacid catalysts. Catalysis Communications. 2005;6(2):147-152. 